\title{
A GESTÃO ESCOLAR DEMOCRÁTICA E PARTICIPATIVA: UM OLHAR PARA AS HABILIDADES, COMPETÊNCIAS, PERSPECTIVAS E DESAFIOS DOS DIRECTORES ESCOLARES DO MUNICÍPIO DA CAÁLA
}

\author{
THE DEMOCRATIC AND PARTICIPATORY SCHOOL MANAGEMENT: A LOOK AT THE \\ SKILLS, COMPETENCES, PERSPECTIVES AND CHALLENGES OF SCHOOL DIRECTORS IN \\ THE MUNICIPALITY OF CAÁLA
}

\author{
Mário Graça da Costa ${ }^{1}$ \\ Francisco Zacarias Enoque ${ }^{2}$ \\ Henriques da Costa Graça ${ }^{3}$
}

RESUMO. O presente Artigo tem por objectivo compreender como a gestão escolar Democrática desenvolve e exerce as suas funções, visando identificar conceitos e reconhecer habilidades, perspectivando o futuro e os grandes desafios das escolas no que tange a gestão democrática, como elementos necessários para gerir. $O$ problema de pesquisa é: como a gestão escolar democrática e participativa desenvolve e exerce as suas funções no ambiente escolar no Município da Caála? O tema da pesquisa A Gestão escolar Democrática e Participativa: Um olhar para as habilidades, perspectivas e desafios dos directores escolares do Município da Caála, surgiu a partir de reflexões realizadas nas aulas da Disciplina de Organização e Gestão Escolar no Curso de Licenciatura em Psicologia do Instituto Superior Politécnico Caála - Polo Universitário do Bailundo. Para a elaboração do presente artigo, utilizou-se a pesquisa quanti-qualitativa e exploratória, e as informações foram colectadas por meio de entrevistas e questionáris Adoc com quatro directores das escolas Públicas do Município da Caála - Província do Huambo, um Coordenador do Polo Universitário do ISPC, quinze estudantes do $4^{\underline{O}}$ Ano de Licenciatura em Ensino Primário e Psicologia, ambos profesores e directores de algumas escolas públicas. A importância da gestão democrática é por o Director ser o indivíduo

\footnotetext{
I Doutorando em Educação na linha de pesquisa em Organização e Gestão de Centro Educativos pela Universidade Internacional Iberoamericana do México - UNINI MÉXICO e Professor do Instituto Superior Politécnico Caála - Angola - Huambo. Mestre em Educação na Especialidade de Organização e Gestão de Centros Educativos pela Universidade Europeia de Atlântico - Espanha; Pós - Graduado em Pedagogia e Gestão de Projectos pela UJES (pós Lato Sensu); Pós - Graduado em Administração Autárquica pelo Instituto de Cooperação Jurídica da Universidade de Lisboa em parceria com a Faculdade de Direito da UJES (pós Lato Sensu); Licenciado em Engenharia Informática e Computadores pela Universidade José Eduardo dos Santos - Angola; Membro efectivo da Ordem dos Engenheiros de Angola com Cédula Profissional n.o 3484; Membro do Grupo de Investigação da UNINI -BR. Email: mario.graca@doctorado.unini.edu.mx; ORCID : http://orcid.org/oooo-oooz-6667-9576.

2 Mestre em Educação na Especialidade de Organização e Gestão de Centros Educativos pela Universidade Europeia de Atlântico - Espanha; Licenciado em Filosofia e Ciências Politicas pela Universidade Católica, Bacharel em Filosofia pelo Seminário Maior Cristo Reis - Huambo, Professor do Instituto Superior Politécnico Caála.

3 Mestrando em Administração de Empresas (MBA) pela UNIATLÂNTICO - Espanha; Licenciado em História e Didática pelo ISPN e Docente do ISPC. Email: costahenriques2or4@gmail.com.
} 

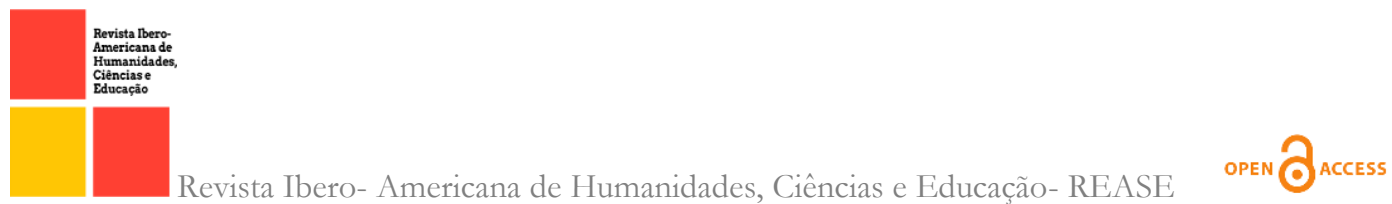

quem deve incentivar e auxiliar a sua equipe, desempenhando o papel de um bom líder. Para que isso aconteça é importante que ele compreenda que o líder sabe dividir as suas responsabilidades e isso faz com que todos sintam-se parte da escola e trabalhem em prol de um processo de ensino e aprendizagem de qualidade.

Palavras-Chave: Gestão escolar Democrática. Participativa. Liderança. Humildade.

ABSTRACT: This article aims to understand how democratic school management develops and exercises its functions, aiming to identify concepts and recognize skills, looking to the future and the major challenges of schools in terms of democratic management, as necessary elements to manage. The research problem is: how democratic and participatory school management develops and exercises its functions in the school environment in the municipality of Caála? The research theme The Democratic and Participatory School Management: A look at the skills, perspectives and challenges of school directors in the municipality of Caála, emerged from reflections carried out in the classes of the Discipline of School Organization and Management in the Undergraduate Course in Psychology at the Institute Caála Polytechnic Superior - Bailundo University Center. For the elaboration of this article, quantitative-qualitative and exploratory research was used, and the information was collected through interviews and Adoc questionnaires with four directors of public schools in the Municipality of Caála Province of Huambo, a Coordinator of the University Pole from ISPC, fifteen students from the 4th year of the Licentiate Degree in Primary Education and Psychology, both teachers and directors of some public schools. The importance of democratic management is because the Director is the individual who should encourage and help his team, playing the role of a good leader. For this to happen, it is important that he understands that the leader knows how to share his responsibilities and this makes everyone feel part of the school and work towards a quality teaching and learning process.

Keywords: Democratic school management. Participatory. Leadership. Humility.

\section{INTRODUÇÃO}

O presente Artigo Científico, aborda o tema A Gestão escolar Democrática e Participativa, olhando para as habilidades, competências, perspectivas e desafios dos directores escolares do Município da Caála. Pois que, uma instituição escolar é um ambiente complexo onde prevalece a diversidade.

Compreender como os sujeitos de unidades educativas concebem a gestão da escola tem sido uma tarefa desafiadora para pesquisadores que atuam no campo da gestão e das políticas públicas, devido à centralidade da gestão escolar ser resultante da intervenção de correlações de forças e interesses diversos de movimentos sociais, de gestores públicos, de agências internacionais como o Banco Interamericano do Desenvolvimento (BIRD), o Banco Mundial (BM) e o 
Fundo Monetário Internacional (FMI), órgãos financiadores de países que seguem suas orientações políticas e econômicas.(JESUS,2019 • p 17).

Sendo que a escola se configura como uma das instituições responsáveis pela formação dos sujeitos da sociedade, cabe a ela o desenvolvimento de valores para que os educandos contribuam para o progresso e boa convivência social (SANTOS, 202I, p.I)

Segundo (RODRIGUES, 202I, p.I4), a gestão educacional é orientada, de um ponto de vista político-pedagógico, pelo princípio constitucional da gestão democrática. Trata-se de um princípio que põe em funcionamento elementos como cidadania e participação.

Pois que a Gestão escolar é o acto de gerir a dinâmica cultural da escola, afinado com as directrizes e políticas educacionais públicas para a implementação de seu projecto político - pedagógico e comprometidos com os princípios da democracia (LÜCK, 2009, p. 24).

A Gestão escolar Democrática, participativa é o acto de gerir dinamicamente qualquer recurso, cultural da escola, de maneira que todos os funcionários e sociedade académica participe dando as suas contribuições com as directrizes e políticas educacionais públicas para a implementação do seu projecto políticopedagógico e comprometidos com os princípios da democracia e com os métodos que organizem e criem condições para um ambiente educacional autónomo, de participação e compartilhamento e autocontrole (FELINO, 2014, p. 40).

No Brasil, além de um princípio pedagógico, a gestão democrática é também um preceito constitucional, quando baseia sua política e ordem jurídica na democracia representativa e participativa, entendendo a participação social e popular como princípio inerente à democracia (GADOTTI, 2014).

A presente pesquisa, realizou-se porque notou-se algunas debilidades na gestão de algunas escolas no Município da Caála no que tange os princípio de boa gestão, falta de colaboração entre algus directores e a comunidade e é de suma importância, visto que, a gestão escolar é o pilar fundamental de qualquer escola, seja ela pública ou privada, portanto cabe ao Director escolar monitorar e coordenar o andamento de todo o ambiente dentro e fora da Instituição. A pesquisa foi realizado a partir de um estudo quantiqualitativo de natureza exploratória e descritiva. A presente pesquisa, justifica-se porque durante a formação do Curso de Licenciatura em Psicologia no ISPC, os estudantes ao apresentar o tema sobre gestão escolar democrática e participativa, bem como alguns 

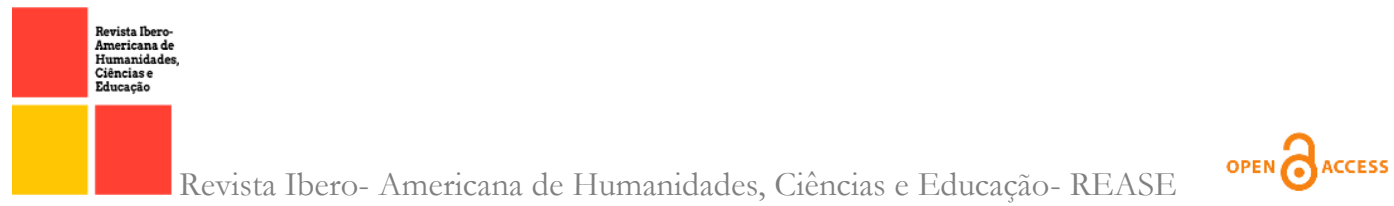

directores escolares, ficaram bastantes curiosos e entusiasmado despertando neles um grande desafio para moldar as escolas no sentido de todos participarem com as suas ideias no sentido de se melhorar o proceso educativo, com vista a se alcaçar a qualidade de ensino e valorizar as opiniões da comunidade do Município da Caála.

Outrossim, o presente tema, é de interesse para o sector educacional, pois implica a proposta de um programa de intervenção para demonstrar os desafios de uma eficiente Gestão Escolar Democrática, Participativa que poderá ser útil como material de consulta para professores, directores e outras entidades educacionais. Ainda o valor prático está dado pela possibilidade da pesquisa servir de ferramenta para detectar os desafios fundamentais que possam existir durante o processo educacional e permitir a implementação de boas práticas de gestão, a partir de um programa de intervenção melhorar o desenvolvimento de gestão e administração das escolas públicas e privadas da Província do Huambo, em particular do Município da Caála.

A presente pesquisa, tem como objetivo geral, compreender como a gestão escolar democrática organiza- se e desenvolve-se, bem como as suas habilidades perspectivas, para trabalhar com os desafíos, tendo em conta a dimensão educacional do seculo $\mathrm{XX}$, e tendo como objetivos específicos; identificar os conceitos de gestão educacional democratica na legislação Angolana e em outros autores; reconhecer habilidades, competências e as pespectivas necessárias para exercer a função de Director de uma escola; descrever as categorias que compõem as habilidades e competências para exercer a função de Director escolar.

Como profesor da Disciplina de Organização e Gestão Escolar do Curso de Licenciatura em Psicologia no Instituto Superior Politécnico Caála e Gestor do Polo Universitário do Bailundo, achamos que, a escola foi muito receptiva e aberta a esclarecer todas as dúvidas para nós. Durante o período de quatro anos, o pesquisador, autor desse trabalho, exercerceu a função de Professor e depois de Coordenador do Polo quando já tinham pasado dois gestores, tornando assim a oportunidade de uma aprendizagem mais rica, pois foi possível acompanhar duas formas de trabalho de equipes diferentes, mas no mesmo cargo. Também no ambiente escolar, foi possível dividir a sala 

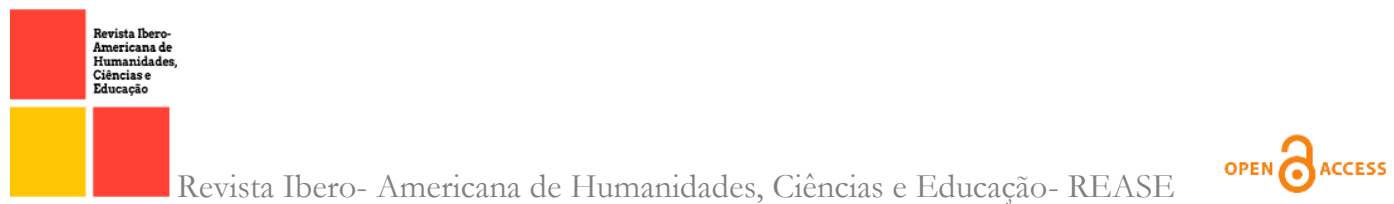

de aulas durante um ano com um colega e professor que já havia atuado por alguns anos na gestão de Instituições escolares ao nível do Município do Bailundo - Província do Huambo. Não há dúvidas de que foram trocas de experiência muito proveitosas e desse professor, em especial, veio o incentivo para aguçar a curiosidade cada vez maior sobre o tema apresentado neste artigo.

De acordo com BUSSMANN (2009, p.4I), administrar é gerir de modo a combinar adequadamente o uso de recursos disponíveis para atingir um objectivo ou conjuntos de objectivos. Já para FERREIRA (2002, p. 35), a "gestão ou administração é o conjunto de normas e funções cujo objectivo é disciplinar os elementos de produção e submeter à produtividade a um controle de qualidade, peara a obtenção de um resultado eficaz, bem como uma satisfação financeira”.

As dimensões que foram tratadas nos pressupostos teóricos desta pesquisa são a função do gestor e liderança. Essa atual seção apresenta os objetivos, método adotado e motivação da pesquisa. $\mathrm{Na}$ segunda seção foram apresentadas algumas reflexões acerca de Gestão Escolar Democrática, participativa e como essa gestão está descrita na legislação Angolana. Também foi abordada a função do gestor escolar e a liderança, descrevendo a importância de o gestor desempenhar essa habilidade no seu trabalho educativo e ainda algumas reflexões do que já foi pesquisado até agora acerca do tema.

Dentre as ações pedagógicas específicas dos diretores de escolas podemos citar: Selecione uma opção: a. As ações técnicas voltadas ao planejamento, a coordenação e ao controle das atividades internas visando a assegurar a eficácia da escola. b. As ações humanas voltadas as suas habilidade de motivação, criação de incentivo adequado, uso de uma gestão participativa. c. As ações Educativas voltadas ao conhecimento conceitual da educação e do conhecimento sobre os sistemas educacionais.

A formação de quadros para administração escolar, inspeção escolar, supervisão e orientação educacional para a educação básica, Ensino médio, deverá ser nos próximos días um grande desafio nos cursos de graduação em Psicologia ou em nível de pós-graduação do ISPC, a critério da instituição de ensino, garantida, nesta formação, a base comum e obedecendo o plano Nacional de formação de quadros e em obdiencia a Lei no 32 20 de 12 
de agosto, que altera a Lei 17_16 de 7 de outubro, Lei de Bases do Sistema de Educação e Ensino na República de Angola. Percebe-se e defende - se a ideia de que o profissional que pretende no futuro ser director de uma escola deve estar habilitado na área da gestão, no ensino médio, na graduação, assim como na pós-graduação. Assim, o profissional, terá uma qualificação que o habilite no seu desempenho de administrar o processo educativo de maneiras satisfatória, contribuindo para a formação integral dos educandos e do desempenho da sua equipe de trabalho, evitando ser nomeado por conveniencia Política e demostrar incopetências diante dos liderados.

Com ênfase na gestão escolar o conceito tem crescido ao longo dos tempos. Segundo OLIVEIRA \& MENEZES (2018, p. 22) :

Gestão escolar é um conceito construído historicamente, impregnado de valores e significados específicos trazidos dentro de um contexto político e educacional, os quais vêm sendo construídos e reconstruídos nos últimos anos. A literatura discute que inicialmente esse conceito estava direcionado aos aspectos mais administrativos da função e que, com o passar dos tempos, de acordo com as mudanças sociais e históricas reafirmadas pela legislação em vigor, passou a buscar o teor mais pedagógico e político da palavra.

O conceito apresentado por Oliveira e Menezes (2018) descreve que o papel do gestor tem mudado ao longo dos tempos, hoje o gestor não é visto somente administrando, mas sim é alguém que participa ativamente dentro dos demais âmbitos escolares.

No dizer de HONORATO (2012 p. 3) traz o enfoque que "o conceito de gestão participativa envolve, além dos professores e outros funcionários, os pais, os alunos e quaisquer outros representantes da comunidade que estejam interessados na escola e na melhoria do processo pedagógico". Levando em consideração a promoção de uma gestão ativa, as funções podem ser compartilhadas com os sujeitos da comunidade escolar. Isso não isenta responsabilidades, mas promove uma gestão participativa dentro da escola.

Segundo LÜCK (20II) entende que o trabalho educacional demanda de um esforço compartilhado, realizado a partir da participação de todos. Essa gestão pode determinar responsabilidades, oportunidades e autonomia aos membros que estejam ligados direta ou indiretamente ao processo educacional.

A legislação angolana, traz a gestão educacional de forma a perceber que a educação, posta desta forma, revela maior responsabilidade nos sujeitos que atuam nas 

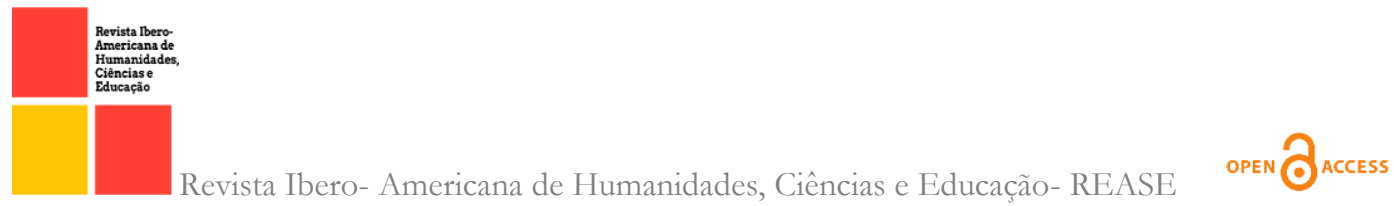

escolas sejam elas públicas ou privadas. A democracia dentro das escolas, pode ser descrita como a participação da comunidade escolar, direção, pais, alunos, professores e funcionários, podendo fechar parceria que beneficiem o ensino. Para que isso aconteça a comunidade escolar deve estar interligada como uma rede para promover a tomada de decisões de forma compartilhada. Essa rede possibilita a visibilidade de um sistema que agrega pessoas em ações e interações sociais.

Segundo GADOTTI (2014), a Administração e gestão escolar Democrática e participativa, constitui uma das áreas de actuação profissional na educação destinada a realizar o planeamento, a organização, a liderança, a orientação, a mediação, a coordenação, o monitoramento e a avaliação dos processos necessários à efectividade das acções educacionais orientadas para a promoção da aprendizagem e formação dos alunos.

No entanto, afirma-se que a gestão democrática implica, principalmente, o repensar da estrutura de poder da escola, tendo em vista sua socialização.

\footnotetext{
A socialização do poder propícia a prática da participação colectiva, que atenua o individualismo; da reciprocidade, que elimina a exploração e da autonomia que anula a dependência de órgãos intermediários que elaboram políticas educacionais das quais a escola é mera executora (DEMO, 1994, p. 21).
}

Pois que a Gestão escolar é o acto de gerir a dinâmica cultural da escola, afinado com as directrizes e políticas educacionais públicas para a implementação de seu projecto político - pedagógico e comprometidos com os princípios da democracia (LÜCK, 2009, p. 24).

Para Lück (2009, p. 24) a gestão está pautada no ato de gerir a dinâmica cultural da escola, afinado com as diretrizes e políticas educacionais públicas para a implementação de seu projeto político-pedagógico e compromissado com os princípios da democracia e com os métodos que organizem e criem condições para um ambiente educacional autônomo de participação e compartilhamento e autocontrole.

Deste modo, o principal objetivo é envolver todos os interessados e potencializar as suas participações, promovendo um ambiente onde são formuladas propostas e buscando soluções que visem atender toda a demanda daquele ambiente.

PEREIRA \& CARON (2015, p. 3) defendem que 
Para a implantação de uma gestão democrática, deveremos observar procedimentos que promovam a participação das pessoas, estabelecendo parcerias que fortaleçam as instituições escolares e extraescolares de deliberação coletiva e, ainda, contar com gestores capazes de aplicar normas legais em situações mais diversas possíveis.

Assim sendo, a gestão tem como diretriz ser capaz de promover a participação e a promoção de um trabalho coletivo. Essa ação traz às pessoas a autonomia e o envolvimento para se sentirem responsáveis pelos seus resultados e protagonistas de uma construção de crescimento da escola.

Nessa mesma direção LIBÂNEO (200I, p. 5) traz a importância da participação de todos:

\begin{abstract}
A gestão democrática- participativa valoriza a participação da comunidade escolar no processo de tomada de decisão, concebe a docência como trabalho interativo, aposta na construção coletiva dos objetivos e do funcionamento da escola, por meio da dinâmica intersubjetiva do diálogo, do consenso.
\end{abstract}

\title{
GESTÃO EDUCACIONAL E SUAS DIMENSÕES
}

A proposta é refletir acerca da gestão educacional e suas dimensões, descrevendo os aspectos que caracterizam a gestão escolar. A referida gestão deve ser composta por uma equipe de profissionais responsáveis pelas questões administrativas e pedagógicas da escola e tem como figura principal o diretor. O gestor tem uma função importante no campo da educação e na promoção de conhecimentos da instituição escolar, pois ele responde, administrativamente, por toda a escola.

Segundo essa ótica, PAULO FREIRE (1980) reconhece a escola como espaço de desenvolvimento da aprendizagem, um ambiente de relação mútua, diálogo e de respeito entre todos os sujeitos que compartilham esse espaço. $\mathrm{O}$ gestor no papel de mediador da escola, torna-se articulador ao assumir, frente à comunidade, o compromisso de oferecer qualidade e um bom funcionamento da escola, desempenhando seu papel com habilidade de liderança.

LÜCK (2008) descreve liderança como uma ação, o gestor pode ser influência positiva a todos, garantindo o funcionamento da escola com foco na aprendizagem dos alunos, mantendo a coerência dentro de todo o trabalho educacional e promovendo o 
desenvolvimento em todos os segmentos. Aseguir, apresentaremos uma tabela com carateristícas de lideraça

Quadro no r: Atitudes identificadas em pessoas que expressam comportamentos de liderança

\begin{tabular}{c|l}
\hline Aceitação a desafios & Gosto pelo trabalho \\
\hline Autoconfiança & Iniciativa \\
\hline Autocontrole & Inteligência emocional \\
\hline Autodeterminação & Inteligência social \\
\hline Comprometimento & Laboriosidade \\
\hline Dedicação & Maturidade psicológica e social \\
\hline Determinação & Motivação \\
\hline Empatia & Ousadia \\
\hline Empreendedorismo & Perseverança \\
\hline Entusiasmo & Persistência \\
\hline Espírito de equipe & Proatividade \\
\hline Expectativas elevadas & Resiliência \\
\hline Flexibilidade & Tolerância à crise \\
\hline
\end{tabular}

Fonte: LÜCK, Heloísa. Liderança em gestão escolar. Vozes, 20o8, p. 74

Desta feita, com estas características, LÜCK (20II) destaca, também, quatro valores que considera orientadores da ação participativa na escola. A saber, a ética pelo respeito ao ser humano, a solidariedade mediante o reconhecimento do valor inerente de cada pessoa, e equidade pelo reconhecimento de que as pessoas necessitam de atenção em situações diferenciadas ou desfavoráveis e o comprometimento na ação dos envolvidos no processo pedagógico.

A partir da descrição da importância do gestor escolar desenvolver a liderança, MENEGHETTI (2013) ressalta que o líder constrói a função, restaura e aperfeiçoa, tornando-se assim um artesão do seu trabalho. Ainda, segundo MENEGHETTI (2013, p. 32), o líder tem três características fundamentais que são:

a) superioridade de potencial humano de nascimento, no que se refere ao talento de fazer e coordenar;

b) superioridade de conhecimento e práxis sobre atitudes e profissões particularmente solicitadas pela sociedade local ou múltipla; 
c) superioridade de realização devido a decisões intuitivas.

Segundo MENEGHETTI (2013), o sujeito líder tem potencial natural, conhece as necessidades e tem intuição. Essas características auxiliam no processo de liderar e têm a ação dentro de si. O instinto de liderança dá-se frente a um problema e a resolução da crise.

A escola deve ser gerida por gestores líderes que saibam servir e construir um ambiente de harmonia entre todas as partes para que exista funcionalidade de valores e produção.

Então, pode-se destacar que gerir é lidar com um complexo de relações humanas, deixando de ser apenas aspectos administrativos e burocráticos. Desta forma, um dos grandes desafios da gestão é unir diversas especificidades em interesse de objetivos comuns. Sendo assim, a gestão exige comprometimento na sua ação e esse é o diferencial do gestor que exerce a liderança de forma ativa e que garante um bom funcionamento que impulsiona a todos. (PEREIRA, 2018).

Para HONORATO (2012), o que se pode verificar é que o verbo liderar está empregado com importância vital para a efetivação da gestão democrática e participativa. Gestão conjunta e organizada tendo como condições de sua concreta atuação quando existe a aproximação entre escola, pais e comunidade na promoção de educação de qualidade do estabelecimento de ambiente escolar aberto, em que os alunos possam experimentar os princípios da cidadania.

Segundo (SANTOS, 2021, p.19), gestor, enquanto cargo que exerce uma pessoa, percebe que a liderança proporciona um ambiente de crescimento, autonomia e escuta. Executar essa função não é tarefa simples, é um desafio diário, exigindo, principalmente, empatia para lidar com as diferenças. Mas o ato de promover a participação é o diferencial que uma gestão democrática proporciona garantindo bons resultados.

PARENTE (2017) assegura que o diretor assume papel fundamental na escola, onde deve ser proporcionado o diálogo e a harmonia entre os sujeitos que compõem a escola. $\mathrm{O}$ ambiente escolar é o local onde todos devem se sentir minimamente felizes, é local de aprendizagem e construção, a gestão escolar tem papel de tornar esse ambiente harmônico.

Nesta mesma ótica, AMORIM (2017) descreve que a gestão inovadora exige que todos participem do processo e contribuam para a consolidação de mudanças significativas no ambiente da escola. Desta forma, criando uma cultura escolar e educacional que traga 
uma visão de totalidade da vida escolar e que contribua para o desenvolvimento de habilidades e competências que irão fortalecer o trabalho do gestor, tendo a participação de equipes colaborativas e inovadoras.

Para NICOLINI (2015) o ato de oportunizar à comunidade escolar o amplo acesso à instituição de ensino e participação direta na tomada de decisões permite que possa ser conhecido melhor o trabalho que a instituição desenvolve. RAMOS (2019) destaca que o principal papel do gestor é saber acompanhar mudanças e auxiliar a ampliar a capacidade de realização da organização escolar, cativando a atingir potencial pleno e a tornar uma instituição que traga orgulho profissional a seus integrantes. Logo, debemos lembrar que, qualquer pessoa tem necessidade de alcançar os seus objectivos e assumiras suas responsabilidades como condição de elevação de sua imagem, identidade social e profissional, principal mente quando se fala de estudantes universitários. De lembrar que, numa das instituição onde foi conduzida entrevista e aplicado alguns questionários, isto é, no Instituto Superior Politécnico Caála, ensinam os seus estudantes a terem espírito de empreenderem, financiado os projectos dos estudantes e professores. Um dos lemas da quela Instituição Superior segundo o Director Geral (CHIPINDO,202I), é Ensino, pesquisa e Extensão, onde tanto os professores como os estudantes, são obrigados a apostarem na pesquisa.

\section{COTIDIANO ESCOLAR}

O Cotidiano escolar, representa "o conjunto de práticas, relações e situações que ocorrem efectivamente no dia-a-dia de uma instituição de educação, episódios rotineiros e triviais que, ignorando por vezes os planejamentos, constituem a substância na qual se inserem crianças ou jovens em processo de formação.” (GALVÃO, 2004, p. 28).

Por exemplo no Brasil, existe o Programa Dinheiro Direto na Escola (PDDE) que consiste no repasse anual de recursos às escolas públicas do ensino fundamental estaduais, municipais e do Distrito Federal e às do ensino especial mantidas por organizações nãogovernamentais (ONGs), desde que registradas no Conselho Nacional de Assistência Social (CNAS). Esta, seria uma boa politica educacional a ser herdada pelo governo Angolano para manter não só as insfra-estruturas, mas também a criação de melhores 
condições para professores, alunos e outros. Em Angola e com destaque no Município do Bailundo, nas suas comunas como Bimbe, Hengue, Luvemba e Lunge, existe até ao momento a chamada educação selvagem onde as crianças do ensino primário, recebem aulas de baixo de árvores considerada como uma escola e salas de aulas com directores de escolas que quando as aulas terminam, tinha que levar os quadros e livros como se fosse um gabinete. Logo quando se dá aulas de forma selvagem, o ensino é tradicional.

\section{GESTÃO PEDAGÓGICA}

Segundo (LÜCK, 2009, p.139), o processo de articulação entre concepções, estratégias, métodos e conteúdos, assim como de esforços, recursos e ações, com foco direto na promoção da aprendizagem e formação dos alunos.

\section{LIDERANÇA COMPARTILHADA}

No entender de (LÜCK, 2009, p. 139), Corresponde à prática de tomada de decisão e atuação colegiada por consenso (e não por votação) em que todos os participantes têm espaço e o usam para influenciar os rumos e as condições do desenvolvimento que se pretende promover.

\section{MISSÃO DA EDUCAÇÃO EM ANGOLA}

No país, as políticas educacionais, são regulamentadas através Lei no 32 _20 de 12 de agosto, que altera a Lei 17_16 de 7 de outubro Lei de Bases do Sistema de Educação e Ensino, conforme a Constituição da República de Angola de 2oro. Atualmente a Educação no mundo, passa por reformulações e adaptações para acompanhar a evolução industrial e tecnológica e sua inserção no campo educacional vem fomentando mudanças nas metodologias, nos perfis dos directores, docentes e dos alunos. Dentre as mudanças que aconteceram recentemente, é possível destacar a quebra do paradigma segundo o qual, os professores deixam os modelos tradicionais de metodologia de ensino onde o aluno era um ser passivo, e os professores únicos detentores do conhecimento. Pois que em Angola, a 

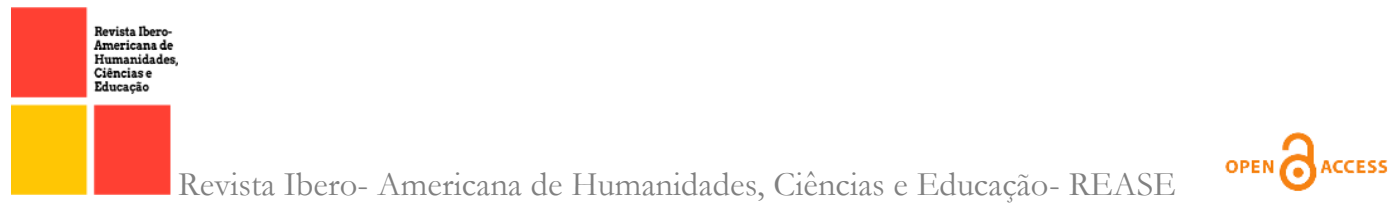

Educação é um processo planificado e sistematizado de ensino e aprendizagem que visa preparar deforma integral o individuo para as exigências da vida individual e colectiva.

A educação nos termos do n. ํ $_{1}$ do Artigo 20 da Lei no ${ }^{32}{ }_{2} 20$ de 12 de Agosto Que altera a Lei 17_16 de 7 de Outubro Lei de Bases do Sistema de Educação e Ensino em Angola, é um processo planificado e sistematizado de ensino e aprendizagem que visa preparar deforma integral o individuo para as exigências da vida individual e colectiva.

Nos termos da Lei no 32_20 de I2 de Agosto Que altera a Lei 17_i6 de 7 de Outubro Lei de Bases do Sistema de Educação e Ensino em Angola, estabelece os Objectivos gerais e Estrutura das Escolas, O Director coordena, organiza e gerência todas as actividades da escola, auxiliado pelos demais componentes do corpo de especialistas e de técnicosadministrativos, atendendo às leis, regulamentos e determinações dos órgãos superiores do sistema de ensino e às decisões no âmbito da escola e pela comunidade.

Nesta fase da Pandemia da Covid-I9, Segundo (COSTA, YAVORSKI \& SANTOS e CAMPOS, 202I), é necessário que os gestores escolares, professores da Província do Huambo, devem apostar seriamente na utilização de ferramentas tecnológicas, para melhorarem as suas práticas pedagógicas, nas pesquisa, no sentido de mudarmos o paradigma da educação tradicional para uma educação moderna onde as competências tecnológicas e investigativas dos estudantes dos cursos de formação de professores, requerem um olhar atento por parte das entidades de direito.

Neste sentido, segundo Costa; Yavorski; Santos e Campos (2021, p. 50), é de suma importância as entidades governamentais, investirem nos meios tecnológicos para apetrechamento das escolas de formas a se formar bons quadros para melhor servirem a sociedade educativa angolana e enfrentarem os desafios da era digital, onde a educação dos futuros directores e professores deve ser o centro das atenções dos governantes.

\section{METODOLOGIA}

O tipo de pesquisa foi bibliográfica, exploratória e descritiva de natureza quantitativa e qualitativa (Pesquisa-acção). Tendo em vista as características da pesquisa, utilizou-se a metodologia de pesquisa - acção, por ser uma metodologia voltada para intervenção, 
desenvolvimento e mudança no âmbito de grupos, organizações e comunidades (SIMÕES, 2016 \& MARÔCO, 20II).

Este estudo qualitativo e quantitativo tem como objetivo, compreender como a gestão escolar Democrática desenvolve e exerce as suas funções, visando identificar conceitos e reconhecer habilidades, competências e perspectivando o futuro e os grandes desafios das escolas no que tange a gestão democrática, como elementos necessários para que os directores do Município da Caála, consigam dar conta dos grandes desafíos da gestão democrática no sentido de se melhorar a qualidade do processo de ensino e aprendizagem nas escola públicas e privadas.

\section{PARTICIPANTES}

O estudo contou com um universo de 20 participantes, sendo, 15 estudantes universitários do $4^{-}$Ano dos cursos de formação de professores 4 Directores de algunas escolas públicas e I Coordenador do Polo Universitário do ISPC, Instituição de Ensino Superior Privada, Aprovada por Decreto Presidencial no 132/17, Artigo 7º, publicado em Diário da República de Angola I SÉRIE-NNo 98 de Junho de 2017, sendo:

- I Coordenador do Polo Universitário do Bailundo afecto ao Instituto Superior Politécnico Caála;

- 8 estudantes do Curso de Licenciatura em Ensino Primário;

- 5 estudantes do Curso de Licenciatura em Psicologia de Educação;

- 4 Directores de escolas

Quadro n. 2: Participantes da Pesquisa

\begin{tabular}{|c|c|c|c|}
\hline /o & Designação & $\begin{array}{cc}\text { N. } & \text { de } \\
\text { Participantes } & \end{array}$ & $\begin{array}{l}\text { Nível } \\
\text { Académico }\end{array}$ \\
\hline & $\begin{array}{lll}\begin{array}{l}\text { Coordenador } \\
\text { Universitário }\end{array} & \text { do } & \text { Polo } \\
\text { Un } & & \\
\end{array}$ & I & Mestre \\
\hline & $\begin{array}{l}\text { Estudantes do Curso de Licenciatura em } \\
\text { Ensino Primário e Psicologia }\end{array}$ & 15 & $4^{\circ}$ Ano \\
\hline & Directores de escolas públicas & 4 & Licenciados \\
\hline & Total: & \multicolumn{2}{|l|}{20} \\
\hline
\end{tabular}

Fote: Própria 

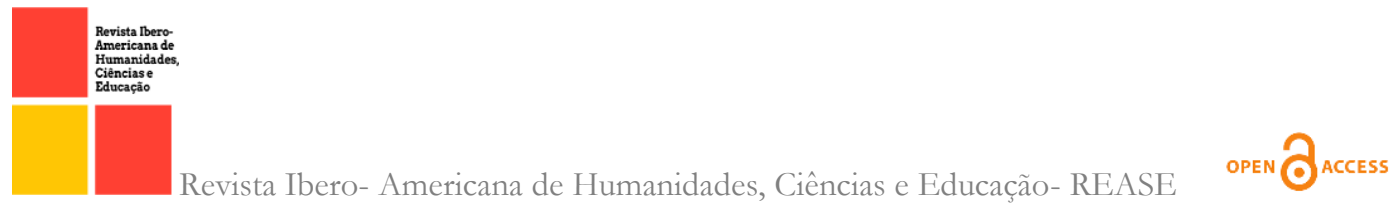

No entanto, do presente estudo e analisando a tabela $n . \stackrel{o}{I}_{1}$, conclui-se que a percentagem maior de estudantes que participaram da investigação, são do curso de licenciatura em Ensino Primário.

\section{INSTRUMENTO DE PESQUISA}

Utilizou-se um questionário Ad Hoc bifásico com perguntas de multiplas escolhas, publicado na plataforma Googleforms, entrevistas e questionários manuais aplicados no Instituto Superior Politécnico - Caála contendo perguntas sobre dados sociodemográficos e sobre a formação de directores escolares desde a pespectiva da gestão escolar Democrática, e algunas entrevistas, visando identificar conceitos e reconhecer habilidades, competências e perspectivando o futuro e os grandes desafios das escolas no que tange a gestão democrática no século XXI, a participação da comunidade e olhando para formação continuada.

\section{A ANÁLISE DE DADOS}

Utilizou-se para análise e processamento dos dados, os Softwares Excel e SPSS (Statistical Package for the Social Sciences) e o Microsoft Worde que para RUDIO (200o) é uma fase metodológica que objetiva obtenção das informações da realidade. Como instrumento de ordenação e tabulação das informações coletadas, se utilizou médias, percentagens, estão apresentados em estatística descritiva; uma vez analisados quantitativamente, foram produzidos gráficos e tabelas para se conhecer as realidades dos estudantes do $4^{-}$Ano dos cursos de Licenciatura em Ensino Primário, Licenciatura em Psicologia ambos do Instituto Superior Politécnico Caála e algusn Directores com mais de 16 anos de experiência das escolas públicas e privadas disponiveis a participar da pesquisa depois de lhes explicar qual era o objectivo da mesma.

Em dizer que, durante as entrevistas, por causa da Pandemia da Covid - 19, está a se exigir nas escolas o cumprimento obrigatório das medidas de biosegurança, o distanciamento físico, o uso obrigatório de mascara, a exibição do Certificado de vacinação 

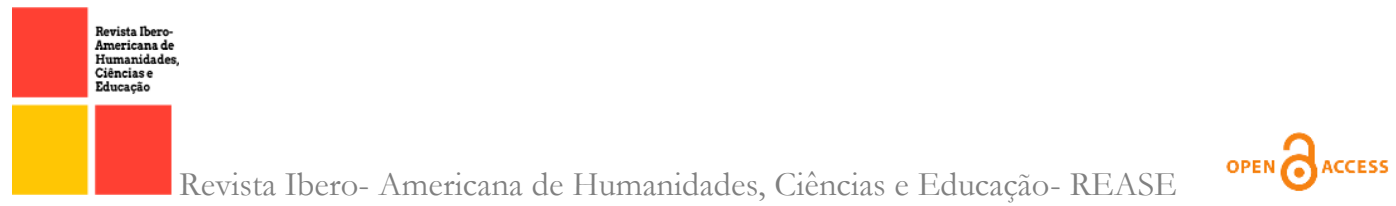

cumprindo as regras impostas pelas alíneas $(a, b), c), d$ ), e e) do artigo n.. 8.. do Decreto Presidencial n. ${ }^{\mathrm{O}}$ I8o/2I de 29 de Novembro sobre Prevenção, Monitoramento e Controle da Transmissão do virus SARS - COV-2 , e, por esse motivo, a escolha do número de participantes foi de forma intencional e reduzido devido as restrições ao recebimento de visitantes.

Quanto aos dados qualitativos, foram analisados por meio da Análise de Conteúdo de BARDIN (2009, p.I2I), conduzida por em três fases: “I. A pré-análise; 2. A exploração do material; e, por fim, 3. O tratamento dos resultados: a inferência e a interpretação.

Quanto aos dados qualitativos, foram analisados por meio da Análise de Conteúdo de BARDIN (2009, p.I2I), conduzida por em três fases: “I. A pré-análise; 2. A exploração do material; e, por fim, 3. O tratamento dos resultados: a inferência e a interpretação.

No presente artigo, buscou-se também realizar uma discussão a partir dos dados da análise sistemática com experiências nacionais e internacionais consideradas relevantes para a compreensão do conceito de Gestão democrática, Gestão Pedagogica, Habilidades, Gestão participativa na educação e percebeu-se que, em nível internacional, são muitas as práticas que têm tratado de definir estes conceitos, com maior destaque o Brasil, Espanha e Estados Unidos. No entanto traduzem um perfil de sujeito e nível educacional que não condiz com a realidade angolana e com maior destaque de alguns directores escolares estudantes dos cursos de Licenciatura em Psicologia e Ensino Primário do ISPC com dificuldades de perceber a Gestão democrática, a gestão participativa e os grandes desafíos do seculo XX para com a gestão das escolas.

\section{ASPECTOS ÉTICOS DA PESQUISA}

A pesquisa seguiu todas as determinações referentes aos aspectos éticos, segundo a Lei n. ${ }^{2} 2 /$ II de 17 de Junho da República de Angola. Assegurando o anonimato, o sigilo de todo o material colectado seja, em forma de texto, imagem ou voz. Apenas os investigadores tiveram acesso ao material. Nenhum dos participantes teve gastos financeiros com a pesquisa, não houve quaisquer riscos de ordem física aos participantes e 

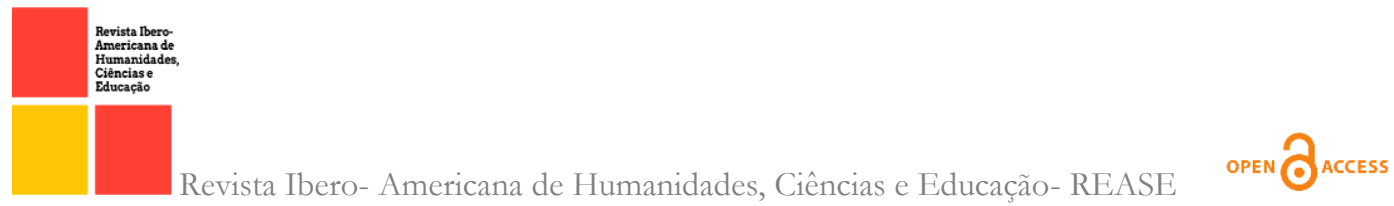

foram garantidos a liberdade dos entrevistados, de recusar a participar ou de retirar seu consentimento em qualquer fase da pesquisa sem penalização ou prejuízo algum.

\section{AMOSTRAGEM, SUJEITOS DA PESQUISA E LOCAL DE ESTUDO}

A pesquisa contou com o método de coleta de dados através de questionários e entrevistas dirigidas a 4 directores de escolas públicas, is estudantes do $4^{\underline{0}}$ Ano do Curso de Licenciatura em Ensino Primário e Psicologia do Instituto Superior Politécnico Caála Polo Universitário do Bailundo, I Cordenador do Polo, perfazendo um total de 20 participantes. Para que o pesquisador tivesse oportunidade de conhecer mais sobre a prática da gestão escolar em cinco estabelecimentos de ensino, sendo quatro públicos do ensino Secundário ( Liceu n. ${ }^{\circ} 4$ de Abril, Colégio Público Comandante Marien Ngoambi da Caála, Escola Primária n.o 20 - Caála e a Escola Primária 4 de Abril - Caála ) e uma Instituição de Ensino Superior Privada ( ISPC-Polo Universitário do Bailundo. Segundo GIL (2008 p. I09), ' A entrevista é, portanto, uma forma de interação social.

\section{RESULTADOS}

$\mathrm{Na}$ presente tabela, se faz um resumo dos principais resultados provenientes do inquérito aplicados aos Directores de algunas escolas públicas e privadas e estudantes universitarios do Curso de Licenciatura em Ensino Primário do Instituto Superior Politécnico Caála - Polo Universitário do Bailundo, expressados em \% mediante uma escala de verificação de Likert.

Os resultados foram analisados e apresentados em tabelas e gráficos. Do ponto de vista dos directores e estudantes dos cursos de Licenciatura em Ensino Primário, Psicologia do ISPC entrevistados, foi constatado que eles consideram muito importante a formação continuada de directores em matérias de Administração e Gestão Escolar, em Tecnologias de Informação e Comunicação com destaque o manuseamento do Computador, bem como as práticas de gestão sob a perspectiva Democrática, participativa e inclusiva em todas as escolas do País, e em particular da Província do Huambo, Município da Caála para melhor gestão dos centros educativos. 
Quadro n. - 3: Entrevistas feitas aos 4 directores, I Coordenador Directores das escolas públicas e aos is estudantes dos cursos de ensino primário e psicología.

\begin{tabular}{|c|c|c|c|c|c|c|}
\hline ㄲo & Variáveis & Sim & $\%$ & Não & $\%$ & Total \\
\hline & $\begin{array}{l}\text { I. Já ouviu falar de gestão escolar Democrática e } \\
\text { participativa? }\end{array}$ & 6 & 30 & 14 & 70 & 20 \\
\hline & $\begin{array}{l}\text { 2. Alguma vez já teve com alguém que lhe falou sobre a } \\
\text { gestão escolar democrática participativa? }\end{array}$ & 8 & 40 & 12 & 60 & 20 \\
\hline & $\begin{array}{l}\text { 3. De pois de ter ouvido sobre o grande desafios das } \\
\text { escolas e a nessecidade da formação continuada dos } \\
\text { directores escolares achou que isto pode contribuir para } \\
\text { a qualidade do processo de ensino e aprendizagem? }\end{array}$ & 7 & 35 & 13 & 65 & 20 \\
\hline
\end{tabular}

\begin{tabular}{|c|c|c|c|c|c|}
\hline $\begin{array}{l}\text { 4. A participação da comunidade na vida das } \\
\text { escolas do Municipio da Caála pode trazer } \\
\text { inovações, contribuições valiosas para o } \\
\text { desenvolvimento das mesmas? }\end{array}$ & 13 & 65 & 7 & 35 & 20 \\
\hline $\begin{array}{l}\text { 5.A Gestão participativa, Gestão pedagógica, } \\
\text { a Gestão Democrática podem contribuir para } \\
\text { o bom funcionamento das Instituições } \\
\text { escolares do Município da Caála? }\end{array}$ & 13 & 65 & 7 & 35 & 20 \\
\hline $\begin{array}{l}\text { 6.Uma proposta de formação e capacitação } \\
\text { dos directores do Município da Caála sob a } \\
\text { pespectiva democrática, participativa e } \\
\text { inclusiva pode trazer benefícios e } \\
\text { desevonvolvimento nas escolas em termos de } \\
\text { qualidade de ensino? }\end{array}$ & 16 & 80 & 4 & 20 & 20 \\
\hline Total: & 63 & & 57 & & \\
\hline
\end{tabular}

Fonte: Própria

Analisando as respostas do inquérito feito aos Directores e estudantes, percebe-se que os mesmos, apresentam um nível de insatisfação por causa de estarem distante da 
quilo que são os desafíos de uma Gestão escolar Democrática e Participativa, onde se requer o Director como líder com as habilidades e competências para colaborar com a comunidade, com perspectivas de desenvolver e exercer as suas funções para assegurar uma educação participativa e de qualidade aque as politícas públicas necessitam e estas fazer cumprir aos privados.

Entende-se política pública como uma expressão que visa definir uma situação específica em que medidas são propostas a fim de melhorar algum aspecto na sociedade. Paramelhor compreensão dessa expressão, é necessária a análise de cada palavra, separadamente. "Política" é uma palavra de origem grega - politikó - que exprime a condição de participação da pessoa que é livre nas decisões sobre os rumos da cidade, a pólis. Já "público" é um vocábulo de origem latina - publica - e significa povo, do povo, (ALVES, 2021,p.14).

No entanto, olhando para os resultados, verifica-se pouca participação da comunidade nas decisões das escolas do Município da Caála. Pois que, há que se trabalhar muito para inverter este quadro e primar para uma democracia nas escolas, sejam elas públicas ou privadas convista a melhoria a aprimorar nas boas práticas de Gestão e melhorar a qualidade do Processo de Ensino e Aprendizagem.

Figura n. @̊: $_{\mathbf{1}}$ Gráfico percentual dos participantes na pesquisa e sua distribuição

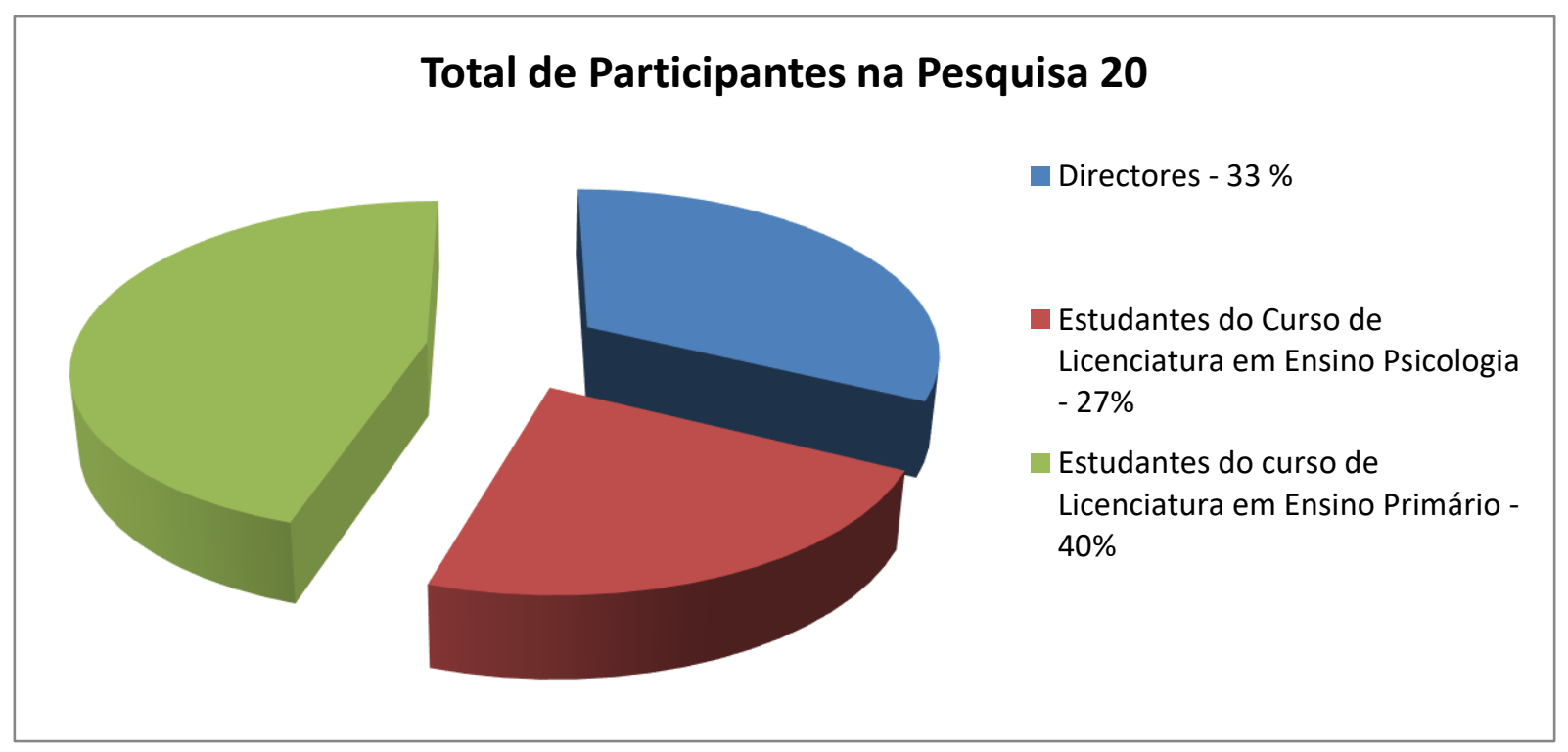

Fonte: Própria, 2021 

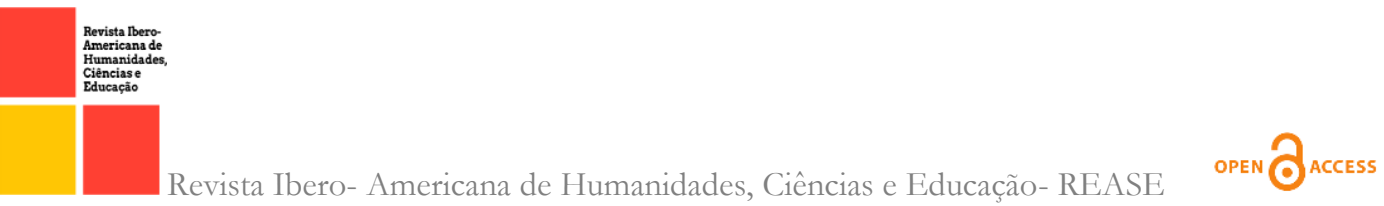

Da presente pesquisa, participaram 5 Directores de escolas que representam uma percentagem de 33\%, 5 estudantes do Curso de Licenciatura em Psicologia que representa 27\% e 8 estudantes do curso de Licenciatura em Ensino Primário que corresponde a 40\%, totalizando uma amostra de 20 individuos correspondente a $100 \%$. Olhando para idoneidade das pessoas entrevistadas, podemos dizer que, precisa-se muito investir na formação de directores escolares em Angola e em particular no Município da Caála para melhor organização das escolas no sentido de se garantir a qualidade de ensino que se quer no País. É muito importante que, a comunidade participe das acções da escola, que haja democracia na gestão, haja motivação e desenvolvimento de espírito comprometido com o trabalho educacional, onde os participantes da comunidade escolar reconhecem em si os valores correspondentes aos valores educacionais e a perspectiva da dedicação do Director, empenho, competências e disposto a contribuír para uma educação de qualidade, formação continuada do seu quadro docente, aprendizagem dos seus alunos, de formas a alcançarem os objectivos esperados e reconhecer os resultados produzidos.

No contexto da dimensão da gestão democrática, fica evidente que o olhar geral dos segmentos estudantes, agentes educacionais e professores apontam as fragilidades de forma mais objectiva. Quanto aos aspectos positivos de análise dessa dimensão, os diferentes segmentos, com destaque para os representantes de pais, analisam a gestão democrática e participativa como consolidada e contribuindo para a qualidade do processo de ensino e aprendizagem no sistema educativo.

De maneira geral, comparando os resultados dos inquérito dos directores escolares entrevistados e dos estudantes do $4^{-}$Ano dos curso de Licenciatura em Ensino Primário e Psicologia, tem que se trabalhar bastante na formação dos futuros profesores e directores, pois que eles todos deram pareceres favoraveis e consideram bons os aspectos expostos anteriormente no inquérito, mais é necessário trabalhar em políticas educacionais que favoreçam uma melhor comunicação a todos os níveis onde todos possam consultar as suas dúvidas e expressar suas preocupações mediante uma informação precisa que responda às expectativas de toda comunidade, dos profesores e gestores escolares. Insto demostra que, todos estão curiosos a ter uma nova proposta de Gestão. 


\section{DISCUSSÃO E CONCLUSÃO}

Figura n. $\mathbf{0}_{2}$ - I Perg. Já ouviu falar de gestão escolar Democrática e participativa?

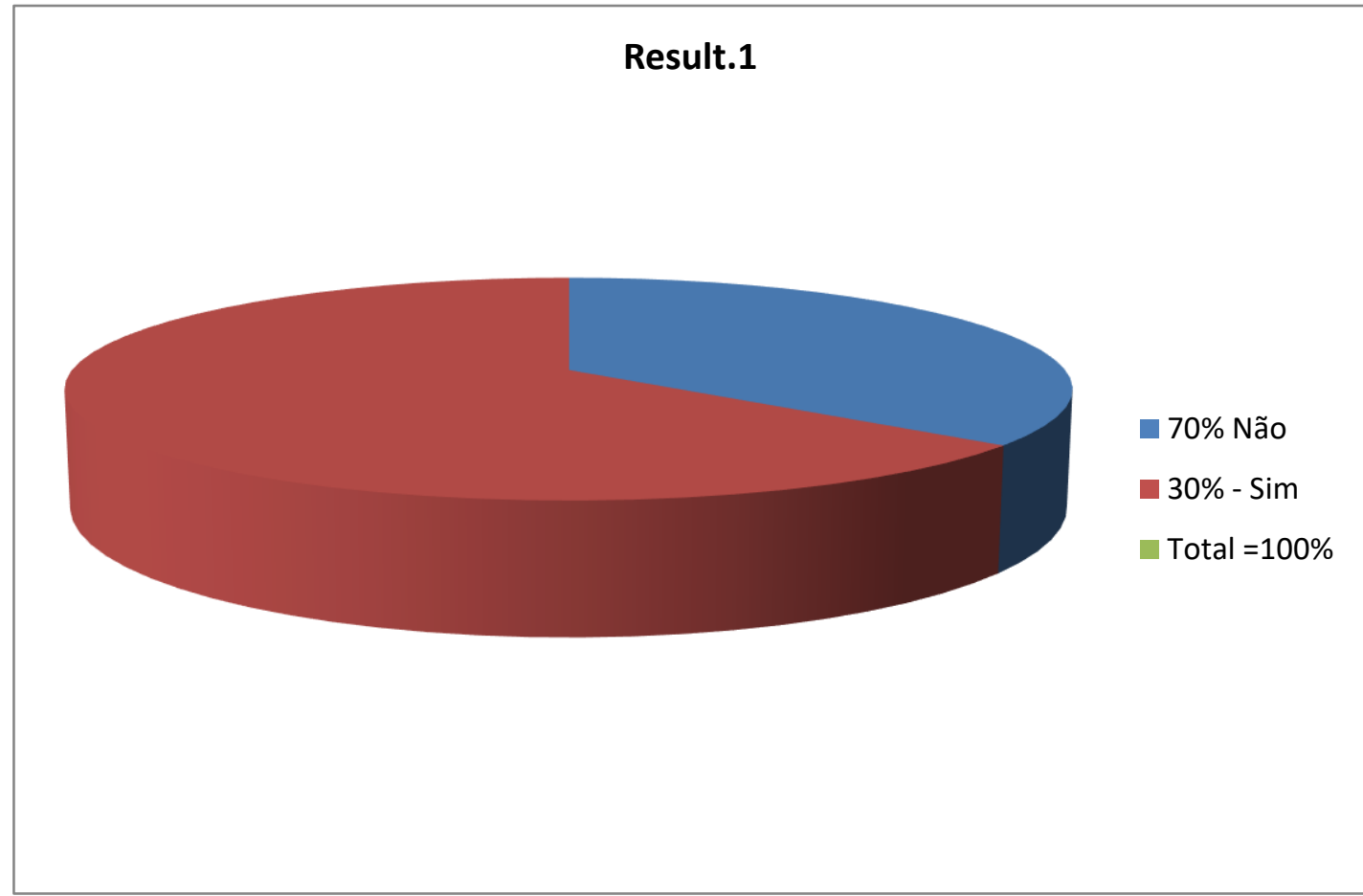

Fonte: Própria, 2021

Observou-se que 30\% já ouviram a falar de administração e gestão escolar democrática e participativa e $70 \%$ não, pois que a partir destes resultados se torna necessário a implementação de um projecto de palestras e seminários de formas a permitir um incremento da qualidade de ensino nos próximos anos e mostrar os grandes desafíos da Gestão Democrática e participativa.

Uma das principais críticas que podemos fazer em relação a esta meta consiste no fato dela considerar o critério do mérito para o provimento dos cargos de directores escolares que tinha que se ter em conta. $O$ mérito pode ser entendido como um degrau vertical que visa à chegada ao cargo por titulação, desta maneira, a formação em gestão sugere ser uma questão chave, importante para o provimento do cargo de Director de escola, (MATTEDI, 2018, p.17) 
Figura n.ㅇ 3-2 Perg. Alguma vez já teve com alguém que lhe falou sobre a gestão escolar democrática participativa?

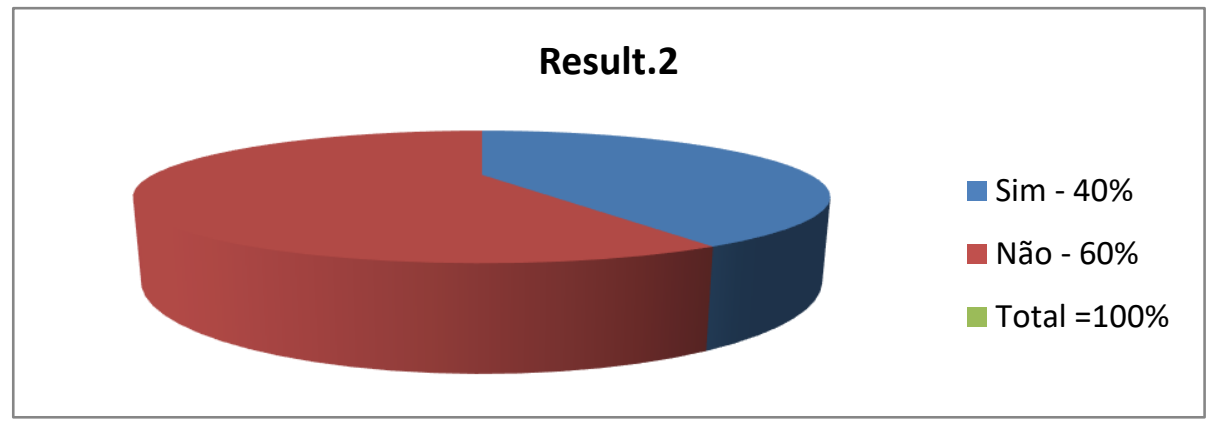

Fonte: Própria, 2021

No presente gráfico, verifica-se que, $40 \%$ dos entevistados já ouviram falar de Gestão Democratica e participativa e 60\% nunca. isto mostra que, os Directores e a comunidade, anda interessada a participar das decisões das escolas caso sejam solicitados.

O conceito de gestão escolar é relativamente novo, e a partir da década de noventa é que foi evidenciado na literatura e aceito dentro do contexto educacional, como proposta para superar a visão restrita da administração. Esse conceito está assentado na mobilização dinâmica do elemento humano, no talento, como forma de criar oportunidades educacionais, transformando a identidade das escolas, oportunizando e criando novas dimensões para o contexto das escolas, (BRAGA, 2018, p. 19).

Figura4 - 3 Perg. De pois de ter ouvido sobre o grande desafios das escolas e a nessecidade da formação continuada dos directores escolares achou que isto pode contribuir para a qualidade do processo de ensino e aprendizagem?

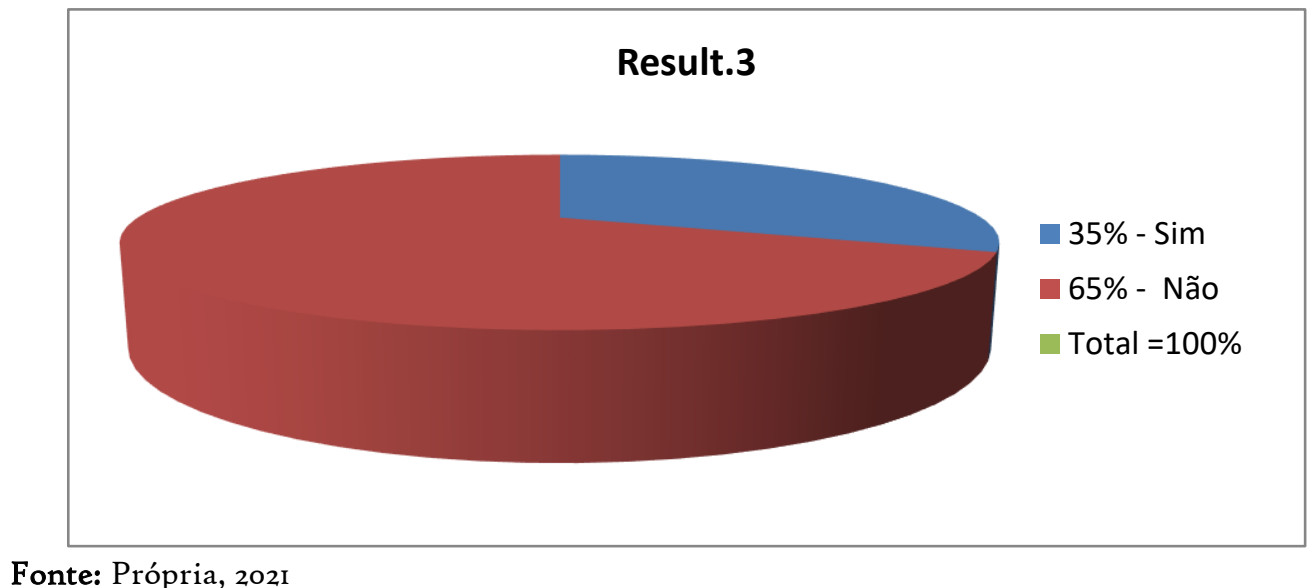


Os entrevistados, depois de terem ouvido sobre o grande desafios das escolas e a nessecidade da formação continuada dos directores escolares, $35 \%$ acharam que isto pode vir a contribuir para a qualidade do processo de ensino e aprendizagem e por um mal entendido da maioria e como estão abituados com uma gestão tradicional, $65 \%$ disseram que não vai contribuir porque a gerência estará sub tutela da comunidade e o Director vai perder autoridade.

Apesar da percentagem mais alta, estar contra, mais, há que se pensar a longo prazo, recolher as experiências dos outros, eliminar as soluções burocráticas, e tratar de distinguir entre a mera introdução das normas do status e a educação transformadora e de qualidade como um desafio para todos.

Figura 5- 4 Perg. A participação da comunidade na vida das escolas do Municipio da Caála pode trazer inovações, contribuições valiosas para o desenvolvimento das mesmas?

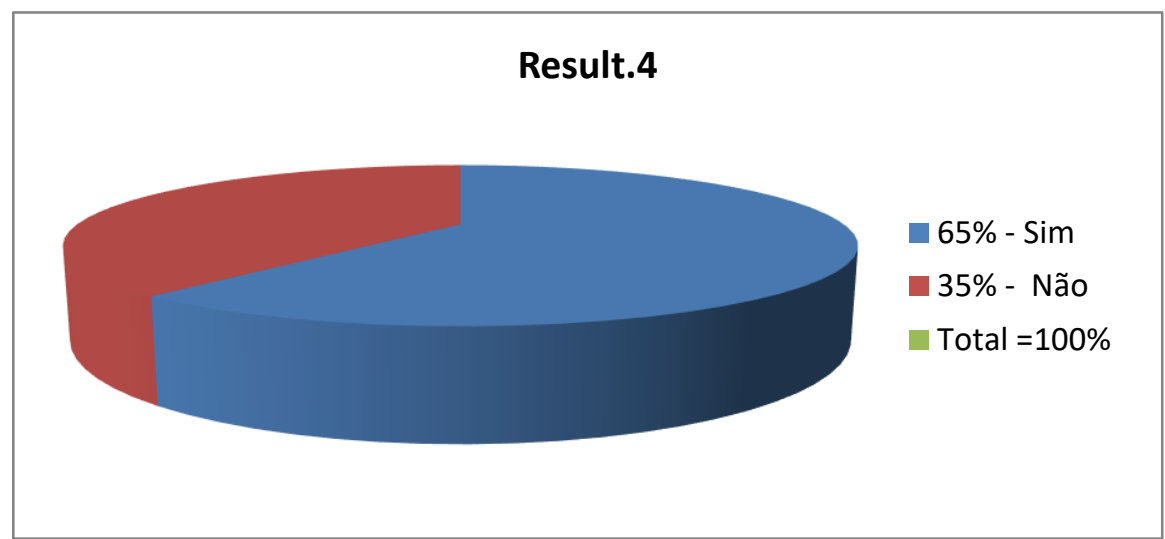

Fonte: Própria, 2021

Os resultados obtidos na discussão da $4^{\underline{a}}$ pergunta, mostram que, $65 \%$ das pessoas entrevistadas acham que a participação da comunidade na vida das escolas do Municipio da Caála pode trazer inovações e contribuições valiosas para o desenvolvimento das mesmas e 35\% não acreditam, o que denota uma grande debilidade e resistência dos responsáveis de algunas escolas em trabalhar com a comunidade para uma gestão mais trasparente e eficiente. 
Segundo (CARVAJAL et al., 2017), a educação pode servir para criar modelos humanos e comportamentos sociais funcionais a tipos específicos de desenhos políticos e económicos, mas se educam mediante métodos democráticos, participativos, críticos, é possível encontrar como resultado do processo docente, pessoas livres, que reajam a favor ou contra quão postulados originalmente se consideravam princípios dos modelos aos que queria formar.

Figura 6-5 Perg. A Gestão participativa, Gestão pedagógica, a Gestão Democrática podem contribuir para o bom funcionamento das Instituições escolares do Município da Caála?

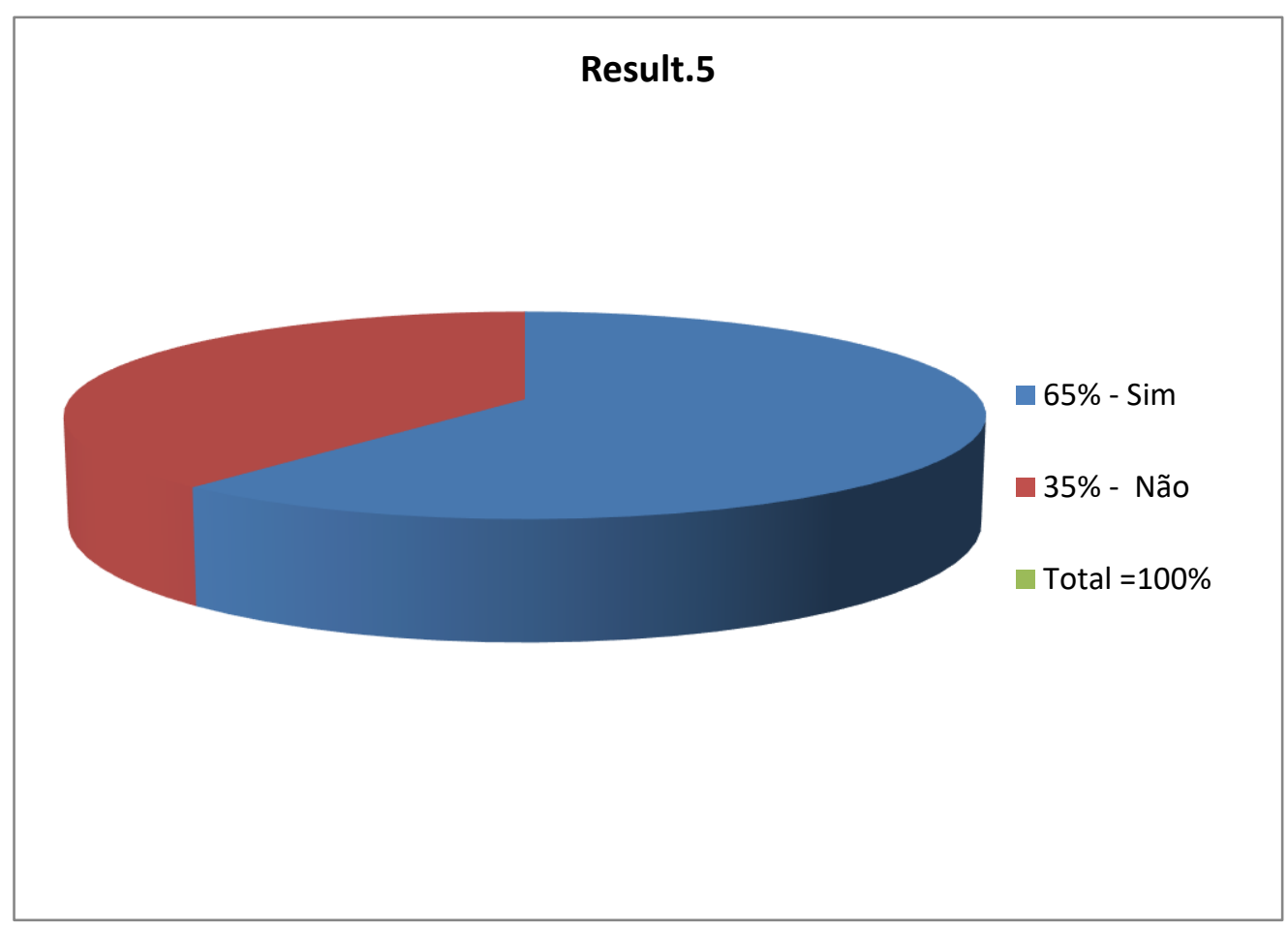

Fonte: Própria, 2021

Os resultados obtidos na discussão da $5^{\underline{a}}$ pergunta, mostram que, $65 \%$ das pessoas entrevistadas acham que a Gestão participativa, Gestão pedagógica , a Gestão Democrática podem contribuir para o bom funcionamento das Instituições escolares do Município da Caála e 35\% não acham que não. 
Figura 7 - 6 Perg Uma proposta de formação e capacitação dos directores do Município da Caála sob a pespectiva democrática, participativa e inclusiva pode trazer benefícios e desevonvolvimento nas escolas em termos de qualidade de ensino?

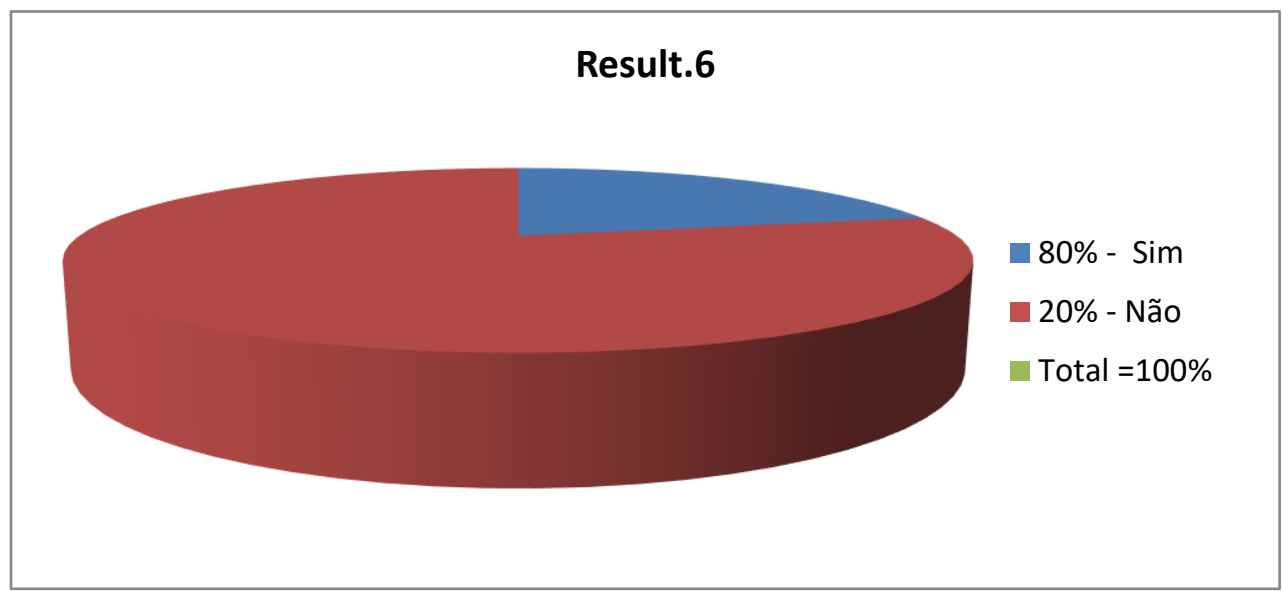

Fonte: Própria, 2021

Dos resultados obtidos na pergunta $\mathrm{n} . \mathrm{o} 6$, temos $80 \%$ de entrevistados que dizem que sim uma proposta de formação e capacitação dos directores do Município da Caála sob a pespectiva democrática, participativa e inclusiva pode trazer benefícios e desevonvolvimento nas escolas em termos de qualidade de ensino, $20 \%$ disseram que não porque o problema de formação é de base e agoram muitos já estão a ir a reforma já não há tempo para formação e depois exercer o cargo.

Segundo ( MOLINA, 202I, p.7), a gestão democrática de uma escola está diretamente relacionada com as formas de atuação do gestor educacional, da coordenação pedagógica, dos docentes, funcionários de apoio, alunos e comunidade, sendo estes que constituem o corpo escolar. É importante compreender que existem hierarquias e autarquias dentro do município que fazem parte direta e indiretamente da gestão democrática no que se refere à escola.

Pois que, a análise teve como foco compreender a Gestão escolar Democrática e Participativa bem como as habilidades, perspectivas e desafios do Secúlo XXI dos Directores escolares no Município do Bailundo. Segundo (PEREIRA, 2018, p. 44), diz que, trabalhar diretamente com pessoas exige equilíbrio e empatia. São ideias diferentes, realidades variadas e potencialidades distintas. Unir todas as 
especificidades em prol de um objetivo comum é o grande desafio, mas é o grande diferencial do gestor escolar que unicamente garante o funcionamento da escola, daquele que a impulsiona para a excelência .

Administração e gestão não são sinónimas, mas processos que se complementam, uma vez que os processos de gestão bem sucedidos estão inter-relacionados a bons procedimentos de administração BRAGA, 2018, p. 19).

\section{CONCLUSÕES}

A legislação angolana, traz a gestão educacional de forma a perceber que a educação, posta desta forma, revela maior responsabilidade nos sujeitos que atuam nas escolas sejam elas públicas ou privadas. A democracia dentro das escolas, pode ser descrita como a participação da comunidade escolar, direção, pais, alunos, professores e funcionários, podendo fechar parceria que beneficiem o ensino. Para que isso aconteça a comunidade escolar deve estar interligada como uma rede para promover a tomada de decisões de forma compartilhada. Essa rede possibilita a visibilidade de um sistema que agrega pessoas em ações e interações sociais.

O pesquisador e escritor do presente trabalho compreende que a gestão é peça fundamental da escola, mas que ela somente consegue fazer um bom trabalho se tiver ao seu lado as pessoas bem formadas e capacitadas para enfrentarem qualquer desafio para o engradecimento da Comunidade. Assim sendo, é de suma importância a necessidade de propor à organização da escola com fundamentos democráticos participativos e inclusivos. É preciso envolver toda a comunidade, encaregados de educação, profesores e comunidade no processo de tomada de decisões e na elaboração de ações dentro do ambiente escolar, fortalecendo vínculos e potencializando as aprendizagens.

\section{REFERENCIAS BIBLIOGRÁFICAS}

ALVES, Nazaré dos Santos Costa. Gestão democrática em escolas públicas municipais rurais: possibilidades e perspectivas. 2020.

AMORIM, António. Gestor escolar inovador: educação da contemporaneidade. 2017. Disponível em: https://www.redalyc.org/pdf/349/34951I49005. Acesso em: 25 jun. 202I. 


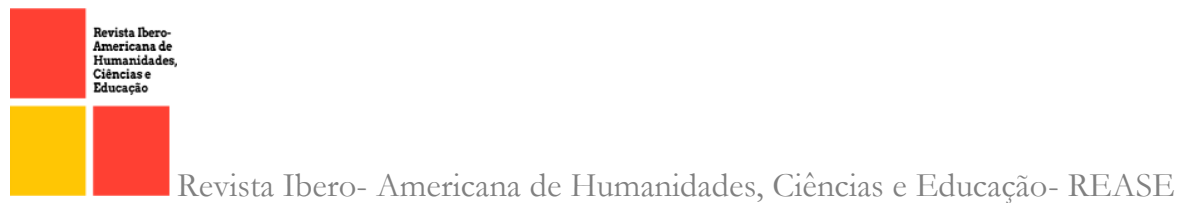

BUSSMANN, António Carvalho.Gestão da Escola e Projeto Político-Pedagógico. In: (im)possibility that yet remains to come. Educational Philosophy and Theory,42(5-6), 2009

BUSSMANN, Antônia Carvalho. O projeto político-pedagógico e a gestão da escola. Projeto político-pedagógico da escola: uma construção possível, v. 17, p. 37-52, I995.

GONZÁLEZ, José Carlos Negrón; LESCAY, Rosmery Nariño. Tesis de Diploma. 2019.

COSTA, MÁRIO. GRAÇA. da ., Yavorski, R. ., \& Campos, M. A. S. e . (202I). AS COMPETÊNCIAS TECNOLÓGICAS E INVESTIGATIVAS DOS ESTUDANTES DO CURSO DE FORMAÇÃO DE PROFESSORES: UM ESTUDO PARA A PROVÍNCIA DO HUAMBO. Revista Ibero-Americana De Humanidades, Ciências E Educação, 7(12), 47-77. https://doi.org/10.51891/rease.v7i12.3413.

CONSTITUINTE, Assembleia. Constituição da república de Angola. Consultado a, v. II, p. 265-286, 2010.

Cury, C. R. J. (2002). Gestão democrática da educação: exigências e desafios. Revista Brasileira de Política e Administração da Educação, São Bernardo do Campo, v.i8 no 2.

CURY, Carlos Roberto Jamil. A gestão democrática na escola e o direito à educação. 2007. Disponível em: https://seer.ufrgs.br/rbpae/article/view/r9i44 Acesso em: I4 out. 2020.

DEMO, Pedro. Educação e qualidade. Papirus Editora, 1995.

FELINTO, Paola Ceccon. Gestão escolar na perspectiva democrático-participativa. 2014.

Ferreira, N. S. C. (2002). Gestão Democrática da Educação para uma Formação Humana: conceitos e possibilidades. Em Aberto, Brasília, v. 17, n.72, p. 167;

FREIRE, Juliana Gonçalves; DIÓGENES, Elione Nogueira. 22- O ensino remoto e o papel da gestão escolar em tempos de pandemia. 2020. Disponível em: https://doity.com.br/media/doity/submissoes/artigo5639ac7a6482313439436f4e809a2599a12136a8-segundo_arquivo Acesso em: 02 jun. 2020.

FREIRE, Paulo. cuidado, escola! desigualdade, domesticação algumas saídas e dividindo opiniões multiplicando cultura. Editora brasiliense, 1987. Ia edição, 1980. Disponível em: https://edisciplinas.usp.br/pluginfile.php/32786o9/mod_resource/content/r/Cuidado\%20 Escola Acesso em: 20 jun. 2021.

GADOTTI, Moacir. Gestão democrática com participação popular. Acesso em, v. I4, 2014.

GADOTTI, Moacir. Gestão democrática da educação com participação popular no planejamento e na organização da educação nacional. In: Conferência Nacional de Educação. 2014. 

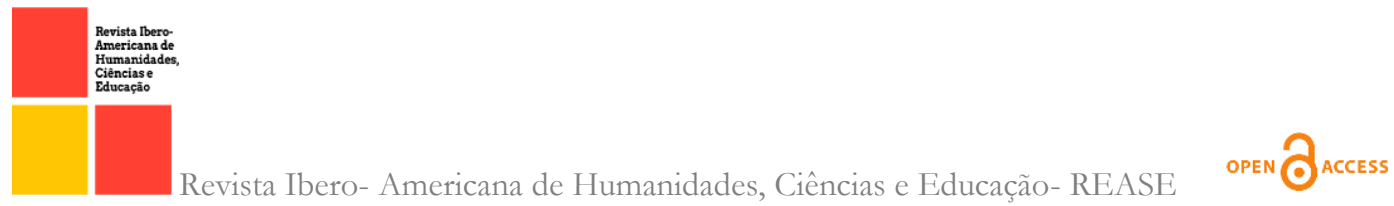

GALVÃO, Izabel. Cenas do cotidiano escolar: conflito sim, violência não. Petrópolis,

GIL, Antonio Carlos. Como elaborar projetos de pesquisa. 5. ed. São Paulo: Atlas,

GIL, Antonio Carlos. Como elaborar projetos de pesquisa. 5. ed. São Paulo: Atlas, 20 Io.

GONZÁLEZ, José Carlos Negrón; LESCAY, Rosmery Nariño. Tesis de Diploma. 2019.

HONORATO, Hercules Guimarães. O gestor escolar e suas competências: a liderança em discussão. 2012. Disponível em: https://www.anpae.org.br/iberoamericano2012/Trabalhos/HerculesGuimaraesHonorato_ res_int_GT8. Acesso em: 04 fev. 2021. 43

HONORATO, Hercules Guimarães. O gestor escolar e suas competências: a liderança em discussão. 2012. Disponível em: https://www.anpae.org.br/iberoamericano2012/Trabalhos/HerculesGuimaraesHonorato_ res_int_GT8. Acesso em: 04 fev. 2021.

JESUS, Gregório Luís De et al. Concepção (ões) de gestão escolar no processo de implementação das eleições de gestores escolares no município de Tucano/BA. 2019.

LAKATOS, E. M. e MARCONI, M. de A. Técnicas de pesquisa: planejamento e execução de pesquisas, amostragens e técnicas de pesquisas, elaboração, análise e interpretação de dados. 3. ed. São Paulo: Atlas, 1996.

LIBÂNEO, José Carlos. O Sistema de Organização e Gestão da Escola. 20or. Disponível em: https://www.faal.com.br/arquivos/complm/Semana2Texto4.pdf. Acesso em: o9 abr. 2021.

LIBÂNEO, José Carlos. Organização e gestão da escola: teoria e prática. Goiânia:

LIMA, Licínio. Por que é tão difícil democratizar a gestão da escola pública? 2018. Disponível em: https://www.scielo.br/j/er/a/YCPpdwGWZshhVyhjwpzHZtp/?lang=pt\&format=pdf. Acesso em: 25 maio 2021.

LIMA, PCM et al. Gestão democrática na escola do campo UMEIEF José Bonifácio Barbosa de Andrade Sumé-PB. 202I.

LÜCK, Heloísa et al. Dimensões da gestão escolar e suas competências. Curitiba: Editora Positivo, v. I, 2009.

LÜCK, Heloísa et al. Heloisa. Liderança em gestão escolar. Petrópolis, RJ: Editora Vozes, 2008. 

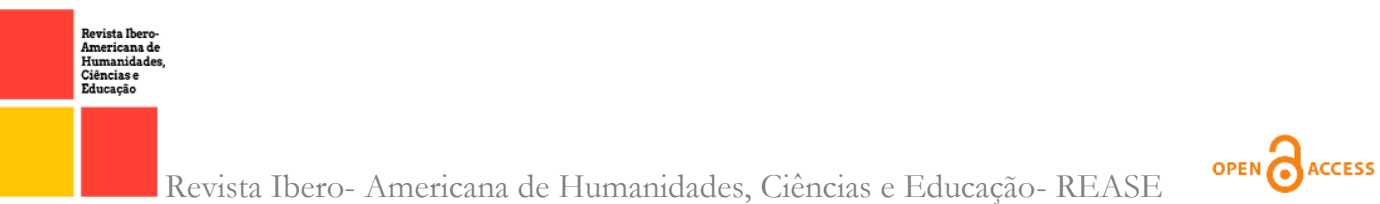

LÜCK, Heloísa. A gestão participativa na escola. ed. Vozes, 20II. Série de Cadernos em Gestão.

LÜCK, Heloísa. Dimensões da gestão escolar e suas competências. 2009. Disponível em: https://edisciplinas.usp.br/pluginfile.php/2190198/mod_resource/content/I/dimensoes_li vro Acesso em: I2 ago. 2020.

LÜCK, Heloísa. Liderança em gestão escolar. ed. Vozes, 2008. Série de Cadernos em Gestão.

MATTEDI, VERÔNICA; DEMOCRÁTICA, CONSELHOS ESCOLARES E. GESTÃO; RANÇOS, AVANÇOS E. MESTRADO EM EDUCAÇÃO.

MENEGHETTI, Antonio. A psicologia do líder. 5. ed. Recanto Maestro, RS: Ontopsicológica Editora Universitária, 2013.

MENEGHETTI, Antonio. Dicionário de Ontopsicologia. 2. ed. Ver. Atual. Recanto Maestro, RS: Ontopsicológica Editora Universitária, 2012.

MOLINA, Mônica Castagna; PEREIRA, Marcelo Fabiano Rodrigues; BRITO, Márcia Mariana Bittencourt. A práxis de egressos (os) da LEdoC UnB na gestão das escolas do campo: caminhos para resistência à Matriz Nacional Comum de Competências do Diretor Escolar. Revista Brasileira de Educação do Campo, v. 6, p. e12965-e12965, 2021.

NICOLINI, Luciana Paludo. I2- A gestão democrática e a participação ativa da comunidade escolar. 2015. $44 \mathrm{f}$. TCC (Especialização) - Curso de Especialização em Gestão Escolar, do Programa Nacional Escola de Gestores da Educação Básica, Universidade Federal do Rio Grande do Sul Faculdade de Educação, Santa Cruz do Sul, 2015. Disponível em: https://lume.ufrgs.br/handle/Ior83/151651 Acesso em: I2 abr. 2021.

OliVeIRA, Ana Cristina Prado; CARVAlHO, Cynthia Paes. Gestão escolar, liderança do diretor e resultados educacionais no Brasil. 2018. Disponível em: https://www.scielo.br/j/rbedu/a/jshd86G9PYQYGJLpJZqpJdC/abstract/?lang=pt Acesso em: 22 maio 2021.

PARENTE, Juliano Mota. Pesquisas em ciências humanas e sociais. 2017. Disponível em: https://portalperiodicos.unoesc.edu.br/roteiro/article/view/I2535 Acesso em: 25 abr. 202I. 44

PARO, Vitor Henrique. Gestão da Escola Pública: a Participação da Comunidade. 1992. Disponível em: http://rbep.inep.gov.br/ojs3/index.php/rbep/article/view/ro92 Acesso em: ro jun. 2021.

PASSONE, Eric Ferdinando Kanai. 8- Gestão escolar e democracia: o que nos ensinam os estudos de eficácia 2019. Disponível em: 

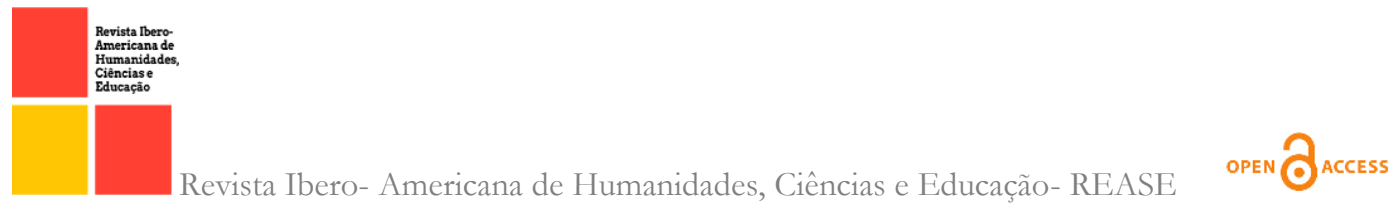

https://www.researchgate.net/publication/333434647_Gestao_Escolar_e_Democracia_o_qu e_nos_ensinam_os_estudos_de_Eficacia_Escolar Acesso em: 5 mar. 2021.

PEREIRA, Elson Rogério Bastos; CARON, Lurdes. A gestão no órgão regional de educação no município de lages, no período de 1972-2012. 2015. Disponível em: https://educere.bruc.com.br/arquivo/pdf2015/19995_10559.pdf Acesso em: I6 out. 2020.

PEREIRA, Larissa Machado. Os desafios da gestão escolar: exercício de liderança para a condução do trabalho em equipe. 2018. 54 f. TCC (Especialização) - Curso de especialização em gestão em supervisão escolar: desafios do trabalho coletivo na escola, Universidade do Vale dos Sinos, São Leopoldo, 2018. Disponível em: http://www.repositorio.jesuita.org.br/bitstream/handle/UNISINOS/7586/Larissa\%2oM achado\%2oPereira_.pdf? sequence $=\mathrm{I} \&$ is Allowed $=\mathrm{y}$ Acesso em: I5 maio 202I.

PERES, Maria Regina. Novos desafios da gestão escolar e de sala de aula em tempos de pandemia. 2020.

Disponível

em: https://periodicos.ufpe.br/revistas/ADED/article/viewFile/246089/36575 Acesso em: 02 jun. 2020 .

RAMOS, Sarah Daniele de Oliveira. Gestão escolar: gestor escolar e conselho participativo. 2019. Disponível em: http://www.faccrei.edu.br/revista/index.php/revistadialogo-e-interacao/article/view/46/30 Acesso em: 13 maio 2021.

REGINATTO, Tatiane; ROSA, Daiani Clesnei da; MARTINS, Silvana Neumann; DIESEL, Aline. Educação empreendedora e gestão escolar: um desafio da escola contemporânea. 2015. Disponível em: https://periodicos.uninove.br/dialogia/article/view/605ı. Acesso em: 2 março. 2020.

RODRIGUES, Krislânia Damascena. A gestão democrática e a educação de jovens e adultos no Plano Municipal de Educação de João Pessoa (2015-2025): correlatos enunciativos. 202I.

SANTOS, Leticia Martins dos. Gestão escolar: desafios, habilidades e perspectivas. 202I.

SILVA, Givanildo da; SANTOS, Inalda Maria dos. A autonomia na gestão escolar: um olhar sobre a realidade da escola pública em Maceió. 20r6. Disponível em: https://periodicos.ufpe.br/revistas/index.php/ADED/article/view/2515 Acesso em: I3 maio 2021.

SILVA, Maria Charleny de Sousa da; SILVA, Janaina de Sousa da. Gestão democrática da escola e a qualidade social da educação escolar: um longo caminho? 20II. Disponível em: http://www.joinpp.ufma.br/jornadas/joinpp2oII/CdVjornada/JORNADA_EIXO_20II/I MPASSES_E_DESAFIOS_DAS_POLITICAS_DE_EDUCACAO/GESTAO_DEMOC RATICA_DA_ESCOLA_E_A_QUALIDADE_SOCIAL_DA_EDUCACAO_ESCOLAR _UM_LONGO_CAMINHO.pdf. Acesso em: 02 maio 202I Vozes, 2004. 